\title{
A expressividade do futuro professor de Química: recursos verbais e não-verbais
}

The expressiveness of future chemistry teacher: verbal and non-verbal resources

\author{
Tânia Afonso Chaves \\ Francisco Ângelo Coutinho \\ Eduardo Fleury Mortimer
}

\begin{abstract}
Resumo
Este trabalho relata um estudo piloto realizado no âmbito de um projeto de doutorado em Educação - UFMG. O objetivo desta análise foi investigar os recursos verbais e não-verbais utilizados por discentes do curso de química da UFMG em uma atividade de preparação para a docência. A metodologia foi orientada por uma combinação de abordagens qualitativa e quantitativa e a ação comunicativa do futuro docente foi avaliada por meio de análise perceptiva de fitas de vídeo de aulas ministradas por 15 alunos da licenciatura. Os dados encontrados forneceram indícios sobre a pertinência deste trabalho e apontaram para a necessidade de um refinamento metodológico para os estudos posteriores. Quanto à expressividade, os informantes, de um modo geral, utilizaram adequadamente os recursos verbais. A variação melódica e a expressividade nãoverbal constituíram-se os parâmetros em que foram encontradas maiores dificuldades.
\end{abstract}

Palavras-chave: Ação comunicativa; expressividade; comunicação verbal; comunicação não verbal; formação de professores.

\footnotetext{
Abstract

This work reports on a pilot study performed in the context of a Doctoral project in Education. The aim of the analysis reported here was to investigate the verbal and non-verbal resources used by university students of Chemistry in activities of teaching training. The methodology was oriented by a combination of quantitative and qualitative approaches and the communicative action of the future teacher was accessed through a perceptive analysis of record lessons in which 15 university students taught Chemistry to high school students. The data
} 
give evidence of the fusibility of the project and they indicate also that the methodology should be refined for application in the doctoral research. Related to the expressiveness, the study shows that the university teachers used quite well the verbal resources. The main difficulties they faced are related to melodic variation and non-verbal expressiveness.

Keywords: Communicative action; expressiveness; verbal communication; non-verbal communication ; professional development of teachers.

\section{Introdução}

A atividade do professor constitui-se como atividade social na qual as interações constroem os sentidos e as relações em sala de aula. Segundo Mortimer e Scott (2003), há o desenvolvimento gradual do interesse sobre o processo de significação em salas de aula, gerando pesquisas que procuram responder como os significados são construídos e desenvolvidos por meio do uso da linguagem e outros modos de comunicação. A linguagem talvez seja o instrumento mais importante utilizado na prática de sala de aula (MORTIMER e SCOTT (2002; 2003); KRESS et al., 2001). O uso da linguagem pelos professores, no entanto, ocorre no contexto de uma ação comunicativa. Muitos professores são extremamente hábeis nesta competência comunicativa e nas práticas de interação, que envolvem aptidões naturais e experiência. A qualidade da ação comunicativa em sala de aula é determinada por múltiplas dimensões de expressividade, entre as quais se manifestam elementos verbais tais como inteligibilidade de fala, intensidade vocal, qualidade vocal, prosódia e fluência, e elementos não verbais utilizados por seus participantes.

Sabe-se que o uso calculado e dirigido de diversos parâmetros da expressividade pode ser construído, ou seja, o docente pode transformar seus discursos e aprimorar sua ação a fim de produzir estratégias comunicativas mais efetivas e estimulantes para seus alunos. A necessidade de se estudar a expressividade e a ação comunicativa dos professores em situação de interação em sala de aula se deve ao fato de que estas habilidades são importantes e podem contribuir para regular os processos de interação, realizar ações e direcionar processos de construção de significados. Além disso, as estratégias de expressividade utilizadas pelo docente também revelam pistas sobre o falante e funcionam como "chaves de interpretação", sinalizando ao aluno como ele deve agir.

Há, no entanto, uma lacuna nos estudos sobre competência comunicativa em sala de aula e, na formação dos professores, o tema é relegado a um segundo plano ou não é abordado. Como 
conseqüência, para muitos dos futuros professores poderá existir uma dificuldade na preparação e condução de suas aulas.

O interesse pela problemática da ação comunicativa do professor deve-se também à própria evolução da atuação fonoaudiológica junto à educação. Durante muito tempo, esta foi uma história "clínica", em que se preferiu trabalhar com patologias, ou prevenção de alterações ao invés de estudar padrões comunicativos. O resultado prático disso é que pouca atenção foi dada à realidade do trabalho educacional do professor, suas habilidades e os conhecimentos necessários para que os docentes possam ser bem sucedidos na especificidade do trabalho de sala de aula. Acreditamos, portanto, que a compreensão de como os índices ou marcadores de expressividade funcionam em contexto de sala de aula seja um aspecto importante a ser considerado para o planejamento do ensino e formação do professor.

Assim, este trabalho objetiva analisar alguns dos recursos verbais e não verbais utilizados por discentes do curso de química da UFMG em uma atividade de preparação para a docência, visando conhecer as necessidades referentes ao aprimoramento da ação comunicativa de professores.

\section{Um olhar sobre a ação comunicativa dos professores}

A voz do professor tem sido objeto da fonoaudiologia há bastante tempo. Vários pesquisadores têm tomado a voz do docente sob diferentes enfoques: à partir da caracterização do perfil e comportamento vocal do professor (ALMEIDA, MOREIRA, NASCIMENTO, FERREIRA e TRINDADE, 2004); a incidência de queixas vocais e disfonias nessa população (AZEVEDO e ALMEIDA, 2004) a consciência e o conhecimento vocal por parte do professor; as estratégias para o enfrentamento dos problemas vocais enfrentados pelos docentes, dentre outros. Entretanto, são ainda poucos os trabalhos sobre expressividade do professor, pois relativamente pouca atenção foi dada a esse aspecto.

Chieppe (2004) investigou, por meio de um Grupo Focal, os conteúdos e conceitos relativos à expressividade direcionada à prática docente, presentes no discurso de estudantes do último ano de Pedagogia de uma Universidade Pública. O conceito de expressividade esteve presente, entretanto, não como um recurso valorativo para a prática docente e em seus enunciados.

Arruda e Ferreira (2004) realizaram uma pesquisa sobre a expressividade de professoras: análise de recursos vocais. $\mathrm{O}$ objetivo desse trabalho foi avaliar, por meio da análise perceptivo- 
auditiva, a qualidade da voz, a variação de loudness e pitch, o alongamento da sílaba, a velocidade de fala, a pausa e a articulação, presentes em trechos de fala de quatro professoras do ensino médio, em contexto profissional, partindo do julgamento de futuros professores quanto à sua expressividade oral. A clareza e objetividade da professora mais bem avaliada, destacada pelos alunos, justificou-se pela maneira como essa professora empregou seus recursos vocais. A velocidade de fala, o emprego da pausa, a qualidade da voz e a intensidade vocal foram aspectos valorizados pelos alunos, e determinantes na escolha da ordem de preferência das professoras.

A análise das várias dimensões da expressividade, embora não muito comum, nos parece importante para a compreensão do processo de comunicação e interações em salas de aula. A investigação desse processo foi fortalecida nos últimos anos por meio de trabalhos que procuram analisar a construção do conhecimento científico escolar como um processo que envolve a apropriação pelos estudantes dos significados e da linguagem veiculada pelo professor (MORTIMER e MACHADO, 1997). Ainda assim, algumas questões permanecem, dentre elas: a expressividade do professor apresenta nuances que podem contribuir para delinear diferentes práticas discursivas em sala de aula?

\section{A expressividade}

Ser expressivo é uma habilidade comunicativa fundamental e configura um componente essencial e poderoso para permitir a interação do professor com seus alunos em sala de aula. A expressividade pode ser definida como o produto do bom uso dos recursos disponíveis. Os recursos de expressividade escolhidos para este trabalho podem ser divididos em 2 grandes grupos: expressividade verbal e expressividade não verbal.

$\mathrm{Na}$ avaliação da expressividade verbal, Behlau e Pontes (1995) indicam que podem ser analisados os seguintes parâmetros: 1) Qualidade vocal, que é a impressão geral que se tem a respeito da voz de um determinado sujeito. 2) Pitch, que é a sensação psicofísica da altura, considerando a variação entre sons graves e agudos. Conforme Servilha (2000), situações mais alegres tendem ao uso de sons mais agudos, enquanto as mais sérias inclinam-se aos sons mais graves. 3) Loudness, que é a impressão psicofísica da intensidade julgando-se ser a voz forte ou fraca. 4) Entonação, que se traduz na melodia ou padrão que engloba inflexões e pausas, entendendo a palavra inflexões a partir de Servilha (2000), como a altura vocal que se desloca durante a emissão, em curvas ascendentes - por exemplo, evidenciada pela colocação de uma pergunta convidando o aluno a intervir, complementar; e/ou descendentes - perceptível nas frases declarativas ou quando se quer concluir sua fala, como se estivesse oferecendo o turno de 
fala para o ouvinte. 5) Articulação da fala, que se expressa nos movimentos harmônicos de língua, lábios, bochechas e palato, entre outras estruturas, que garantem a emissão dos sons da fala de forma inteligível. 6) Velocidade de fala, que é o ritmo próprio que cada sujeito imprime à sua fala, segundo sua personalidade. 7) E finalmente a fluência, que é o fluxo suave e contínuo da fala, que além de ser o produto de uma programação cerebral altamente complexa, é também produto da experiência, da visão de mundo e da imagem pessoal do falante.

Gonçalves (2000) ressalta que para falar deve-se usar o tom de voz natural, e a entonação adequada, pois estes são recursos eficientes para uma boa comunicação. Pode-se, com esses recursos, mostrar autoridade e confiabilidade, sem a necessidade de se recorrer a uma voz de comando. A mesma autora complementa dizendo que as inflexões de voz (entonação) estabelecem diferentes curvas melódicas no discurso e, associadas ao recurso da pausa, são essenciais para o "brilho da fala", constituindo elementos muito importantes da comunicação verbal. Sem esses recursos, a fala torna-se muito monótona, tornando-se menos inteligível e eficiente, o que pode levar o interlocutor ao desinteresse.

Segundo Kyrillos (2005), a comunicação verbal será considerada eficiente quando o indivíduo possuir a habilidade de persuadir o outro por meio da palavra. Mas, essa palavra deverá vir acompanhada de uma série de elementos fundamentais, sem os quais perde muito da sua força: a postura corporal, a fluência, o tom de voz, os gestos, a forma de olhar, a linguagem corporal, o entusiasmo ao falar, o domínio do conteúdo, bem como a criatividade e a motivação. Assim, temos que os gestos, expressão facial, postura e aparência, são alguns dos canais nãoverbais da comunicação muito importantes para a efetividade do discurso, pois podem complementar o discurso, modificar ou reforçar as idéias.

Nesse contexto, a utilização das estratégias não-verbais com harmonia de movimentos e naturalidade cumpre o propósito de completar o que se fala, não devendo ser apenas um ato mecânico desvinculado de emoção. Sinais como tristeza, alegria, raiva, medo, dentre outros, podem ser percebidos pela expressão facial, pelos movimentos corporais e pela postura.

Paul Ekman (1999), um dos pioneiros no estudo das expressões faciais, gestos e emoções, classifica os gestos em três categorias: "emblemas", "ilustradores" e "adaptadores".

"Emblemas" são atos não-verbais que têm uma tradução verbal específica. Esse tipo de gesto é pouco utilizado em grupos, sendo mais freqüente quando o silêncio é necessário ou quando queremos conversar com alguém que se aproxima, mas estamos em uma conversa com outra pessoa. 
Os "ilustradores" são gestos mais comuns. São movimentos, realizados principalmente pelos braços e mãos, que acompanham o fluxo da fala e estão intimamente relacionados com ela. Têm um importante papel na efetividade da comunicação e adicionam, esclarecem ou repetem informações transmitidas pela fala, especialmente sobre formas, objetos e relações espaciais.

Os "adaptadores" são atividades ou posições nas quais partes do corpo tomam contato com outras partes, com objetos ou outras pessoas. Eles revelam estados internos de ansiedade, nervosismo ou inibição.

Alguns trabalhos sobre a expressividade não verbal já foram realizados a partir dessas premissas. Mortimer e Santos (2003) demonstraram a importância de se relacionar: linguagem, expressividade não-verbal e emoções em sala de aula. Os autores relatam que os gestos, postura e imagens pressupõem-se mutuamente e por isso integram-se uns aos outros. Desta forma, tornam-se potencialmente significantes e integrados com o discurso. De acordo com Mortimer e Santos (2003) a comunicação não verbal constitui-se parte do processo de comunicação do conhecimento científico em sala de aula.

Deste modo, a habilidade comunicativa faz parte da atividade profissional do professor e pode implicar um uso calculado e mais consciente de diversos parâmetros já citados anteriormente, para um resultado final satisfatório. Assim, este tipo de análise constitui-se em um objeto importante para a formação do professor em geral, e do professor de Ciências em particular.

\section{Metodologia}

Este estudo foi orientado por uma abordagem qualitativa e quantitativa e caracteriza-se por ser um estudo piloto que teve como objetivo geral realizar um exercício analítico para verificar a aplicabilidade da proposta apresentada no projeto de doutorado em Educação UFMG, intitulado A ação comunicativa do professor universitário e o uso de práticas de expressividade em situação de interação em sala de aula. $O$ objetivo específico desta análise foi investigar os recursos verbais e não verbais utilizados por discentes do curso de química da UFMG em uma atividade de preparação para a docência.

Para a coleta dos dados, servimo-nos da gravação em fitas de vídeo de aulas ministradas por quinze alunos da licenciatura do curso de Química da UFMG aos estudantes do Colégio Técnico da mesma instituição. Esses alunos de química encontravam-se no oitavo período do curso de graduação e estavam matriculados na disciplina Prática de Ensino de Química I. Onze 
alunos eram do sexo feminino e quatro do sexo masculino. Inicialmente fez-se uma análise mais geral das fitas de vídeo dos informantes com objetivo de ter uma visão mais descritiva e empírica sobre os dados. Em seguida, os recursos de expressividade utilizados pelos futuros professores de Química foram analisados. Esta análise pode ser considerada perceptivo-auditiva-visual, pois foi feita por meio de observação sistemática de parâmetros relativos a variações entonacionais, padrões de pitch e loudness, análise de velocidade de fala, articulação, pausas e padrões de fluência, além da análise da comunicação não verbal que incluiu gestos e postura dos informantes.

A análise da expressividade verbal, para cada indivíduo, foi realizada de acordo com o protocolo adaptado de Behlau \& Pontes (1995) e foi dividido em: Qualidade vocal (normal ou alterada); pitch (normal, agudo ou grave); loudness (normal, aumentado ou reduzido); articulação (precisa ou imprecisa); pausas (restritas, médias ou freqüentes); fluência (disfluências mais comuns ou menos comuns); e, finalmente, variação melódica (pobre, neutra ou rica). Cada um dos parâmetros analisados fornece uma informação sobre as características de expressividade verbal.

A análise da expressividade não verbal foi realizada de acordo com adaptação da classificação de gestos proposta por Ekman (1999): emblemas, ilustradores e adaptadores. Para esta pesquisa não consideramos os emblemas, pois este é um tipo de gesto pouco utilizado em grupo, sendo mais freqüente quando o silêncio é necessário. Para a análise da postura, utilizamos as orientações de Behlau \& Pontes (1995), que apontam que a postura deve ser equilibrada e têm um importante papel na efetividade da comunicação. A postura foi avaliada como adequada ou inadequada.

Esta análise perceptivo-auditiva e perceptivo-visual, por ser subjetiva, foi realizada por 3 avaliadores: 2 estudantes de Fonoaudiologia da FEAD-Minas (do programa de iniciação científica) e uma fonoaudióloga (especialista em Linguagem, mestre em Lingüística e doutoranda em Educação, primeira autora deste trabalho). Os dados observados por cada avaliador foram comparados e forneceram um relatório com a descrição das estratégias de expressividade utilizadas por cada informante.

A análise quantitativa restringiu-se apenas ao cálculo de ocorrências de respostas, uma vez que, em função do tempo, técnicas estatísticas mais refinadas que envolvem validação de conteúdo, critério e constructo não foram levadas em consideração neste artigo.

Ao final da pesquisa, foi realizada uma palestra para os informantes, com o objetivo de abordar conceitos que tem interesse para o docente e fornecer subsídios para a construção de uma comunicação que facilite a interação e que seja uma ferramenta na ação educacional. 


\section{Resultados e Discussão}

A fim de facilitar a análise dos dados, os resultados serão divididos em três seções. A primeira caracterizará os informantes quanto aos aspectos de expressividade verbal. A segunda apontará para os resultados referentes à comunicação não verbal e a terceira comparará os resultados obtidos com a os dados de Arruda e Ferreira (2004) e Vasconcellos e Otta (2003). Esses resultados possibilitar-nos-ão averiguar quais são os recursos verbais e não verbais utilizados por discentes do curso de química da UFMG em uma atividade de preparação para a docência.

\section{Análise da expressividade verbal}

Como se pode ver pela Tabela 1, que apresenta a caracterização das variáveis verbais, a expressividade verbal é constituída de parâmetros sonoros audíveis, percebidos pelo ouvinte (qualidade vocal; loudness; pitch; articulação; pausas; fluência; e variação melódica). Esta expressividade verbal ocorre em decorrência do movimento coordenado de órgãos fonoarticulatórios e, do ponto de vista estritamente motor, depende da atividade coordenada das pregas vocais, laringe, faringe, palato mole, mandíbula, lábios e língua (KENT e READ, 1992).

\begin{tabular}{|c|c|c|}
\hline Características & Categorias & \% de ocorrência \\
\hline \multirow{3}{*}{ Qualidade vocal } & Normal & $87 \%$ \\
\cline { 2 - 3 } & Alterada & $13 \%$ \\
\hline \multirow{4}{*}{ Pitch } & Normal & $73 \%$ \\
\cline { 2 - 3 } & Agudo & $27 \%$ \\
\cline { 2 - 3 } & Grave & $0 \%$ \\
\hline \multirow{3}{*}{ Loudness } & Normal & $47 \%$ \\
\cline { 2 - 3 } & Aumentado & $13 \%$ \\
\cline { 2 - 3 } & Reduzido & $40 \%$ \\
\hline Articulação & Precisa & $67 \%$ \\
\cline { 2 - 3 } & Imprecisa & $33 \%$ \\
\hline \multirow{2}{*}{ Pausas } & Restritas & $13 \%$ \\
\cline { 2 - 3 } & Médias & $73 \%$ \\
\cline { 2 - 3 } & Freqüentes & $13 \%$ \\
\hline
\end{tabular}




\begin{tabular}{|c|c|c|}
\hline \multirow[t]{3}{*}{ Velocidade } & Lenta & $27 \%$ \\
\hline & Adequada & $54 \%$ \\
\hline & Rápida & $19 \%$ \\
\hline \multirow[t]{2}{*}{ Disfluências } & Mais comuns & $100 \%$ \\
\hline & Menos comuns & $0 \%$ \\
\hline \multirow{3}{*}{$\begin{array}{l}\text { Variação } \\
\text { melódica }\end{array}$} & Pobre & $13 \%$ \\
\hline & Neutra & $73 \%$ \\
\hline & Rica & $13 \%$ \\
\hline
\end{tabular}

Tabela 1 - Caracterização das variáveis verbais em \% de ocorrência

A qualidade vocal foi caracterizada como normal para $87 \%$ dos informantes. Este é um índice considerado alto, visto vários pesquisadores relatam uma alta incidência de queixas vocais e disfonias nesta população (AZEVEDO e ALMEIDA, 2004; CASTRO et al., 2004; DIAS et al., 1994 e DISTÉFANO et al., 2004). Este dado discordante pode ser explicado pelo fato de os informantes (estudantes do 80 período do curso de Química) não terem experiência e tempo de docência suficiente para terem desenvolvido comportamentos vocais inadequados que ocasionam alterações na voz.

Na caracterização de pitch, temos que $73 \%$ dos informantes apresentaram a freqüência sonora vocal considerada normal. Quanto à intensidade sonora, o índice de loudness reduzida foi alto, manifestando-se em $40 \%$ dos informantes. Isto pode dificultar a interação e a construção de sentidos por parte dos alunos visto que grande parte das variações expressivas depende de propriedades físicas da vocalização. A articulação da maior parte dos informantes foi considerada precisa $(67 \%)$, com uso de pausas (73\%) e velocidade de fala adequada (54\%). Mas é preciso considerar que houve um índice alto de imprecisão articulatória (33\%) e inadequação da velocidade de fala (46\%) - lenta ou rápida. Este aspecto nos faz perceber que a execução do comportamento fonatório humano demanda níveis de complexidade que excedem os encontrados em qualquer outra espécie e, para alguns autores, esse conjunto seria o sistema mais avançado encontrado no organismo humano (FAWCUS, 2001).

Quanto as disfluências, foram encontradas apenas as mais comuns, ou seja, é preciso considerar que a disfluência é um aspecto normal da fluência de qualquer falante. Ao longo do fluxo fluente de um período de fala, qualquer indivíduo está sujeito a ter momentos de disfluência. Este é mais um dado que reforça a noção de complexidade envolvida na execução do comportamento fonatório humano. (FAWCUS, 2001). 
A maior dificuldade observada diz respeito à variação melódica. Os informantes tiveram dificuldade de utilizar os parâmetros da comunicação verbal para enfatizar, realçar e garantir a expressividade do seu discurso (apenas $13 \%$ dos informantes apresentaram esta habilidade). A variação melódica, ou aspecto suprasegmental da fala, ou prosódia, é o componente mais importante do domínio lingüístico, e se refere à proeminência relativa ou ênfase a várias unidades dentro do sinal sonoro como mudanças na variação melódica das unidades de fala que conferem a entonação, o ritmo e os padrões de duração (PAUL et al., 2005). Esse resultado talvez possa ser explicado também pela pouca experiência dos informantes com o uso público da voz na situação de sala de aula.

\section{Análise da expressividade não verbal}

O uso de estratégias não verbais pode converter-se em recursos interessantes para maximizar a ação comunicativa do professor. No entanto, as maiores dificuldades apresentadas pelos informantes relacionam-se justamente ao uso dessas estratégias. A maioria de nossos informantes parece apresentar dificuldades em enriquecer seu discurso por meio de gestualidade, e postura. $\mathrm{O}$ uso preferencial de gestos adaptadores pode indicar que os mesmos foram usados para aliviar o nervosismo e a ansiedade. Além disso, a postura foi considerada inadequada para $60 \%$ da amostra, como mostra a Tabela 2. Também esse resultado pode ser explicado pela inexperiência dos informantes. Para muitos, a aula analisada neste trabalho era a primeira experiência docente e o nervosismo e insegurança com a situação se traduziu principalmente numa postura corporal inadequada, que reflete o medo de relacionar-se com os alunos.

\begin{tabular}{l|l|l|}
\hline \multicolumn{1}{c|}{ Características } & \multicolumn{1}{c|}{ Categorias } & \multicolumn{1}{c}{ \% de ocorrência } \\
\hline \multirow{2}{*}{ Gestualidade } & Predominância de adaptadores & $67 \%$ \\
\cline { 2 - 3 } & Predominância de ilustradores & $33 \%$ \\
\hline Postura corporal & Adequada & $40 \%$ \\
\cline { 2 - 3 } & Inadequada & $60 \%$ \\
\hline
\end{tabular}

Tabela 2 - Caracterização das variáveis não verbais em \% de ocorrência

Para Santos e Mortimer, 2003, a análise da expressividade e do comportamento não verbal confere visibilidade a muitos aspectos da interação. Assim, a análise das várias dimensões da expressividade, especialmente a não verbal, pode ser essencial para compreender os processos de interação. 


\section{Comparação dos resultados obtidos com outras pesquisas sobre o mesmo tema}

Podemos, a partir dos estudos de Arruda e Ferreira (2004) e Vasconcellos e Otta, 2003, hipotetizar que possivelmente um professor considerado bom comunicador pelos alunos, apresenta recursos de expressividade tanto verbais quanto não verbais.

Para confrontar os dados de Arruda e Ferreira (2004) com os dados descritos na Tabela 1, foram selecionados dados de 4 (quatro) discentes, nossos informantes, que se aproximavam da descrição das autoras (embora não tenha havido uma concordância de dados em todos os aspectos). Para eleição dos casos prototípicos, tabelas 3 e 4, as performances foram analisadas separadamente, os dados foram comparados e fizemos uma classificação em que os informantes foram classificados em um continuum. A tabela 3 representa as ações com os melhores parâmetros de expressividade e a tabela 4, os piores.

\begin{tabular}{|l|l|l|l|l|l|l|l|l|}
\hline Parâmetro & $\begin{array}{l}\text { Qualidade } \\
\text { vocal }\end{array}$ & Pitch & Loudness & Pausa & Velocidade & Articulação & Fluência & $\begin{array}{l}\text { Variação } \\
\text { Melódica }\end{array}$ \\
\hline Inform. 5 & Normal & Normal & Aumenta & Médias & Adequada & Precisa & + & Rica \\
\hline Inform. 13 & Normal & Agudo & Aumenta & Médias & Rápida & Precisa & + & Rica \\
\hline
\end{tabular}

Tabela 3 - Análise da Expressividade verbal dos informantes que apresentaram melhores parâmetros de expressividade

\begin{tabular}{|l|l|l||l|l|l|l|l|l|}
\hline Parâmetro & $\begin{array}{l}\text { Qualidade } \\
\text { vocal }\end{array}$ & Pitch & Loudness & Pausa & Velocidade & Articulação & Fluência & $\begin{array}{l}\text { Variação } \\
\text { Melódica }\end{array}$ \\
\hline Inform. 3 & Normal & Normal & Reduzida & Freqüente & Lenta & Imprecisa & + & Pobre \\
\hline Inform. 6 & Normal & Agudo & Reduzida & Freqüente & Adequada & Imprecisa & + & Pobre \\
\hline
\end{tabular}

Tabela 4 - Análise da Expressividade verbal dos informantes que apresentaram piores parâmetros de expressividade

Ao analisar as estratégias de expressividade dos casos considerados nas Tabelas 3 e 4, temos que a qualidade vocal e a fluência parecem não ser fatores determinantes para a 
diferenciação da ação comunicativa. Parece existir, entretanto, uma congruência no uso de intensidade (loudness) aumentada, pausas médias, recursos de variação melódica e articulação precisa para os informantes que apresentaram melhores parâmetros de expressividade. Em oposição a esses dados, temos que, na Tabela 4 os dados apontam para pausas freqüentes, que foram utilizadas para organizar o discurso, e não como um recursos de ênfase, loudness reduzida, articulação imprecisa e variação melódica pobre. A ação comunicativa, portanto, parece ser influenciada pelo uso de determinados recursos (articulação precisa) bem como estratégias prosódicas compostas pela variação da velocidade, intensidade (loudness), e pausa (Stephens et al., 1983).

A análise destes parâmetros está associada positivamente com julgamentos subjetivos de indicadores de emoção, e falantes que não podem expressar sua variação melódica são incapazes de exprimir sua emoção com acurácia aos ouvintes (Monnot et al, 2003). Isto ocorre porque uma mesma frase dita com diferentes emoções soa diferente, mostrando que a informação na fala é codificada não somente em seus componentes verbais, semânticos, ou segmentais, mas também por um componente da expressividade do falante. Ao analisarmos os dados da expressividade verbal dos informantes que apresentaram melhores parâmetros de expressividade (pausas médias, variação na velocidade de fala, uso freqüente dos recursos de ênfase, articulação precisa e variação melódica), foi possível perceber que estes parâmetros podem contribuir para marcar a intenção do professor (Mortimer e Scott, 2003) ou, seja, a intenção expressiva deste falante (Bakhtin,1981).

Vasconcellos e Otta, 2003, realizaram uma pesquisa sobre o comportamento gestual de bons e maus oradores durante a comunicação em público. Neste estudo, encontraram que os bons oradores apresentaram maior freqüência e duração de gestos ilustradores, enquanto maus oradores apresentaram maior freqüência e uma tendência a maior duração de gestos adaptadores.

Se retomarmos os dados das Tabelas 3 e 4, que caracterizam casos prototípicos de melhores e piores parâmetros de expressividade verbal, temos que, na Tabela 3 se encontram os informantes 5 e 13. Ao cruzarmos estes dados com a análise da expressividade não verbal desses informantes, temos que os mesmos apresentaram uma maior freqüência de gestos ilustradores acompanhados de uma postura adequada (Tabela 5). 0 mesmo raciocínio pode ser feito para a Tabela 4, ou seja, os informantes 3 e 6 apresentaram uma maior freqüência de gestos adaptadores/postura inadequada (Tabela 5). 


\begin{tabular}{|c|c|c|c|c|}
\hline Parâmetro & Informante 3 & Informante 5 & Informante 6 & Informante 13 \\
\hline Gestualidade & Adaptadores & Ilustradores & Adaptadores & Ilustradores \\
\hline Postura corporal & Inadequada & Adequada & Inadequada & Adequada \\
\hline
\end{tabular}

Tabela 5 - Análise da Expressividade dos informantes 3,5,6 e 13.

Esse resultado concorda com os dados de Vasconcellos e Otta, 2003 e pode ser explicado por um maior nervosismo e insegurança com a situação por parte dos informantes 3 e 6.

Esta pesquisa não teve por objetivo relacionar os dados obtidos para os informantes com o uso que eles fazem de diferentes 'abordagens comunicativas'. Esse conceito é central na estrutura analítica proposta por Mortimer e Scott (2002; 2003) para analisar a forma como os professores podem agir para guiar as interações que resultam na construção de significados em salas de aula. Entretanto, acreditamos que diferentes práticas de expressividade podem interferir nesses padrões de interação.

Este artigo foi desenvolvido em função de um estudo piloto, a fim de realizar uma primeira aproximação com dados referentes à expressividade do professor e verificar a possibilidade e limites metodológicos ao investigar os recursos verbais e não verbais utilizados por docentes.

Uma contribuição desse estudo foi dar um retorno aos informantes para que pudessem refletir sobre os aspectos da expressividade e tentar aprimorá-los no novo estágio que realizariam no contexto da disciplina Prática de Ensino de Química II. Além disso, pelo fato de a maioria dos informantes não terem experiência docente, a gestão das interações e o uso de diferentes abordagens comunicativas também era objeto de aprendizado no estágio no Coltec.

No entanto, mesmo levando em consideração que existe a variável "experiência do docente", bem como a influência de fatores subjetivos, portanto, sem controle absoluto por parte do falante, possam ter influenciado no processo de interações em sala de aula, consideramos a correlação entre expressividade e interação discursiva um aspecto importante que será explorado no trabalho de tese da primeira autora. 


\section{Considerações Finais}

Dificilmente alguém discordaria sobre a importância central da comunicação entre professores e alunos na sala de aula, a chamada interação discursiva, para a elaboração de novos significados pelos estudantes.

Este estudo teve como objetivo geral realizar um exercício analítico dos recursos de expressividade utilizados por docentes. Os dados preliminares demonstraram que é incontestável o fato de que tanto a expressividade verbal quanto a não verbal podem ser parâmetros utilizados para revelar e fornecer a perspectiva sobre como o professor trabalha as intenções e o conteúdo do ensino. Ou seja, o modo pelo qual o docente se comunica pode influenciar na interação e na construção de significados por parte dos discentes.

Pesquisas sobre ação comunicativa de docentes podem ter papel importante na compreensão da atividade do professor em sala de aula. A partir da análise e discussão dos dados aqui apresentados observou-se 0 uso de diferentes recursos de expressividade por parte dos futuros docentes. A ocorrência de diferentes recursos expressivos ilustra as funções que os mesmos podem assumir como elementos das interações discursivas em sala de aula.

Se partirmos do pressuposto de que o docente tem como atividade atuar como mediador do processo ensino-aprendizagem, uma perspectiva educacional em que as práticas comunicativas são investigadas torna-se importante para os dias de hoje. Assim, coloca-se como uma das questões da investigação dos processos comunicativos de sala de aula, a expressividade do professor, em suas múltiplas dimensões, tanto verbais quanto não verbais. Acreditamos que estudar e analisar como esses índices ou marcadores de expressividade utilizados pelos docentes funcionam em contexto de sala de aula; e em que medida determinam a evolução da interação e construção de significados específicos, seja um elemento importante para o planejamento do ensino e para a formação do professor.

Os dados encontrados forneceram indícios sobre a pertinência deste trabalho e sua possibilidade de execução. Entretanto, apontaram para a necessidade de novas pesquisas bem como de um refinamento metodológico para os estudos posteriores. A fim de analisar a expressividade no contexto das práticas discursivas em sala de aula é imprescindível caracterizar a forma como o professor trabalha, as estratégias que utiliza e a visão que apresenta sobre o processo de ensino-aprendizagem. A fim de visualizar, de forma mais objetiva recursos de expressividade não verbais utilizados pelos docentes, alguns testes podem ser adaptados e aplicados, a fim de melhor caracterizar a 
gestualidade. Para pesquisas futuras, o estudo da expressão facial e emoções deve ser aprofundado visto que estas têm um claro papel na manifestação das atitudes do falante. É importante também a visualização de fenômenos prosódicos como a freqüência fundamental, a intensidade e a duração das emissões, a partir da análise acústica. $O$ tratamento destes dados deve envolver técnicas mais refinadas de análise estatística, que não foram levadas em consideração neste artigo.

Finalmente, torna-se necessário um maior número de aulas filmadas devido à necessidade de construir uma visão de conjunto de como uma seqüência de ensino se organiza temporalmente, de comparar diferentes aulas, caracterizar as diferentes dinâmicas discursivas adotadas e identificar evidências de estratégias de expressividade utilizadas pelos professores. Também é imprescindível relacionar as estratégias de expressividade com o tipo de aula, conteúdos disciplinares em questão, envolvimento emocional do professor, dentre outros aspectos.

\section{Bibliografia}

ALMEIDA ACB, MOREIRA D, NASCIMENTO FP, FERREIRA KCC, TRINDADE LLM. Perfil vocal dos professores da rede municipal-estadual do município de Medicilândia-PA. Anais do XII Congresso Brasileiro de Fonoaudiologia e II Congresso SulBrasileiro de Fonoaudiologia;2004 Out 6-9; Foz do Iguaçu, PR. São Paulo: SBFa; 2004.

ARRUDA A. F. E FERREIRA L. P. A expressividade oral de professoras: análise de recursos vocais. Anais do XII Congresso Brasileiro de Fonoaudiologia e II Congresso SulBrasileiro de Fonoaudiologia; 2004 Out 6-9; Foz do Iguaçu, PR. São Paulo: SBFa; 2004.

AZEVEDO L. L, ALMEIDA L. B. Alterações vocais em professores fumantes. Anais do XII Congresso Brasileiro de Fonoaudiologia e II Congresso SulBrasileiro de Fonoaudiologia; 2004 Out 6-9; Foz do Iguaçu, PR. São Paulo: SBFa; 2004.

BAKHTIN, M.M. Speech genres and other late essays. Austin: University of Texas Press. 1981. (edited by c. Emerson and m. Holquist, translated by v.w. mcgee).

BEHLAU M. E PONTES, P. Avaliação e tratamento das disfonias. São Paulo: Lovise, 1995.

CASTRO A. S., PINHEIROS L. F., LEOPOLDINO R. M. , OLIVEIRA T. V., RAMOS S. M. Sinais e sintomas vocais de professores. Anais do XII Congresso Brasileiro de Fonoaudiologia e II Congresso SulBrasileiro de Fonoaudiologia; 2004 Out 
CHIEPPE, D.C. A Fonoaudiologia na formação do professor: estudo sobre a expressividade em sala de aula. Dissertação de Mestrado, Pontifícia Universidade Católica de São Paulo, São Paulo, SP. 2004.

DIAS I. C. G. , CASALECHI S. B., FONSECA R. L. , MADÁZIO G. M. V., MOTA L. F., NASCIMENTO M. A., NUNES C. C. , SILVEIRA A. L., SMITH R. J. Descrição do comportamento vocal do professor universitário.Anais do V Congresso Nacional de Fonoaudiologia; 1994; Petrópolis, RJ; 1994. DISTÉFANO E. G., KOWALSKI T., FIORANI X. Ocorrência de queixas vocais em professores das séries iniciais da rede pública do município de Balneário Camboriú - SC. Anais do XII Congresso Brasileiro de Fonoaudiologia e II Congresso SulBrasileiro de Fonoaudiologia; 2004 Out 6-9; Foz do Iguaçu, PR. São Paulo: SBFa; 2004.

EKMAN, P. Basic Emotions. In T. Dalgleish and M. Power (Eds.). Handbook of Cognition and Emotion. Sussex, U.K. John Wiley \& Sons, Ltd., 1999.

FAWCUS, R. Disfonias: Diagnóstico e Tratamento. 2a Ed. São Paulo: Revinter. 1: 1-18, 2001. GONÇALVES N. A importância do falar bem: A expressividade do corpo, da fala e da voz valorizando a comunicação verbal. São Paulo: Lovise, 2000.

KENT R.D., READ C. The Acoustic Analysis of Speech. Singular Publishing Group, Inc. San Diego, California. 1992.

KRESS, G., JEWITT, C., OGBORN, J. AND TSATSARELIS, C. (2001) Multimodal teaching and learning: the rhetoric of the science classroom. London: Continuum.

KYRILLOS,L. Expressividade - da teoria à prática. Rio de Janeiro: Revinter, 2005.

MONNOT, M., ORBELO D., RICCARDO L, SIKKA S, ROSSA E. Acoustic Analyses support subjective judgments of vocal emotion. Annals of the New York Academy of Sciences. 1000:288-92, 2003. MORTIMER,E F E MACHADO, Andréa H. Múltiplos olhares sobre um episódio de ensino:porque o gelo flutua na água? In: encontro sobre teoria e pesquisa em Ensino de Ciências; Linguagem, cultura e cognição-reflexos para o ensino de ciências, 1997, Belo Horizonte, UFMG 1997. p 139162.

MORTIMER, E. F. E SANTOS. How emotions shape the relationship between a chemistry teacher and her high school students. INT. J. SCI. EDUC., 2003, VOL. 25, NO. 9, 1095-1110.

MORTIMER, E. F. E SCOTT, P. H. Atividades discursivas nas salas de aula de ciências: uma ferramenta sociocultural para analisar e planejar o ensino. Investigações em Ensino de Ciencias v.3 (3). 2002. Public. Eletrônica, http://www.if.ufrgs.br/public/ensino/revista.htm. 
MORTIMER, E.F. AND SCOTT, P.H. Meaning making in secondary science classrooms.

Maidenhead: Open University Press. 2003.

PAUL R, AUGUSTYN A, KLIN A, VOLKMAR FR. Perception and production of prosody by speakers with autism spectrum disorders. J Autism Dev Disord, 2005; 35(2): 205-20

SERVILHA, E.A.M. A voz do professor: indicador para a compreensão da dialogia no processo ensino-aprendizagem. Campinas, 2000. Tese de doutorado em Ciências, Pontifícia Universidade Católica de Campinas.

STEPHENS, K., NICKERSON, R., \& ROLLINS, A. Suprasegmental and postural aspects of speech production and their effect on articulatory skills and intelligibility. In: Hochberg (Ed.), Speech of the hearing impaired: Research, training and personnel preparation. (pp. 35-51).

Baltimore:University Park Press. 1983.

VASCONCELLOS, L R E OTTA,M Comparação do comportamento gestual entre maus e bons oradores durante a comunicação em público. Psicologia em Revista,Belo Horizonte,v.9, n.13, p.153-158, jun.2003;

Tânia Afonso Chaves: Doutoranda. Universidade Federal de Minas Gerais. tania_afonsochaves@hotmail.com

Francisco Ângelo Coutinho. PUC Minas. fac01@terra.com.br

Eduardo Fleury Mortimer. Universidade Federal de Minas Gerais - Faculdade de Educação. mortimer@netuno.lcc.ufmg.br 